J. Dairy Sci. 98:2713-2726

http://dx.doi.org/10.3168/jds.2014-8448

(C) American Dairy Science Association ${ }^{\circledR}, 2015$.

\title{
Inferring causal relationships between reproductive and metabolic health disorders and production traits in first-lactation US Holsteins using recursive models
}

\author{
K. Dhakal, ${ }^{* 1}$ F. Tiezzi, ${ }^{*}$ J. S. Clay, $†$ and C. Maltecca* \\ *Department of Animal Science, North Carolina State University, Raleigh 27695 \\ †Dairy Records Management Systems, Raleigh, NC 27603
}

\begin{abstract}
Health disorders in dairy cows have a substantial effect on the profitability of a dairy enterprise because of loss in milk sales, culling of unhealthy cows, and replacement costs. Complex relationships exist between health disorders and production traits. Understanding the causal structures among these traits may help us disentangle these complex relationships. The principal objective of this study was to use producer-recorded data to explore phenotypic and genetic relationships among reproductive and metabolic health disorders and production traits in first-lactation US Holsteins. A total of 77,004 first-lactation daughters' records of 2,183 sires were analyzed using recursive models. Health data contained information on reproductive health disorders [retained placenta (RP); metritis (METR)] and metabolic health disorders [ketosis (KETO); displaced abomasum (DA)]. Production traits included mean milk yield (MY) from early lactation (mean MY from 6 to $60 \mathrm{~d}$ in milk and from 61 to $120 \mathrm{~d}$ in milk), peak milk yield (PMY), day in milk of peak milk yield (PeakD), and lactation persistency (LP). Three different sets of traits were analyzed in which recursive effects from each health disorder on culling, recursive effects of one health disorder on another health disorder and on MY, and recursive effects of each health disorder on production traits, including PeakD, PMY, and LP, were assumed. Different recursive Gaussian-threshold and threshold models were implemented in a Bayesian framework. Estimates of the structural coefficients obtained between health disorders and culling were positive; on the liability scale, the structural coefficients ranged from 0.929 to 1.590 , confirming that the presence of a health disorder increased culling. Positive recursive effects of RP to METR (0.117) and of KETO to DA (0.122) were estimated, whereas recursive effects from health disorders to production traits were negligible in all cases.
\end{abstract}

Received June 4, 2014.

Accepted December 7, 2014.

${ }^{1}$ Corresponding author: kdhakal@ncsu.edu
Heritability estimates of health disorders ranged from 0.023 to 0.114 , in accordance with previous studies. Similarly, genetic correlations obtained between health disorders were moderate. The results obtained suggest that reproductive and metabolic health disorder and culling due to metabolic and reproductive diseases have strong causal relationships. Based on these results, we concluded that a health disorder (either reproductive or metabolic) occurring in early lactation has a moderate causal effect on the reproductive or metabolic health disorder occurring in later lactation. In addition, direct, indirect, and overall effects of reproductive and metabolic health disorders on milk yields for cows that avoid culling are weak.

Key words: causal effect, health, persistency, structural equation model

\section{INTRODUCTION}

Many health disorders in dairy cows have a substantial effect on the farm economy. The occurrence of a health disorder can cause economic losses due to culling and treatment costs. In addition, health disorders increase the number of potential replacements, impair reproductive efficiency, decrease longevity of cows, and have an adverse effect on animal welfare (Congleton and King, 1984; Britt, 1985; Jakobsen et al., 2003; Dhakal et al., 2013). Health disorders have a direct effect on culling and production traits (Duffield and Herdt, 2000; Drackley, 2006; Esposito et al., 2014). Dechow and Goodling (2008) reported that early culling was a reliable indicator of poor cow health. Several studies (Simianer et al., 1991; Rauw et al., 1998; Koeck et al., 2013b) have reported that an antagonistic relationship exists between milk production and disease resistance.

Beaudeau et al. (2000) reported that metabolic disorders have effects on milk production, reproductive performance, and culling. Ketosis (KETO) and displaced abomasum (DA) were reported as the 2 most frequent metabolic diseases in first-lactation Canadian Holstein cows, with disease frequencies of 4.09 
and $2.66 \%$, respectively (Koeck et al., 2013a). In the United States, Zwald et al. (2004a) reported disease frequencies of $10 \%$ for KETO and $3 \%$ for DA in dairy cows, from producer-recorded data. Similarly, Appuhamy et al. (2009) reported incidence rates of $5.2 \%$ for KETO and $4.1 \%$ for DA for first-lactation US dairy cows. More recently, Parker Gaddis et al. (2012), using producer-recorded health data, reported lactational incidence rates of $3.42 \%$ for KETO and $1.29 \%$ for DA for first-parity cows. Similarly, regarding reproductive efficiency, retained placenta (RP) and metritis (METR) have been reported as the disorders mostly affecting culling risk and depressing the overall productivity of dairy cows by reducing milk yield (Rajala and Gröhn, 1998). Lactational incidence rates of METR reported were $8.71 \%$ (Parker Gaddis et al. 2012), 21\% including RP (Zwald et al. 2004a), and 17.7\% (Appuhamy et al. 2009), including RP and cystic ovaries, in US dairy cows using producer-recorded data.

Production traits such as test-day milk yields, day in milk of peak milk yield (PeakD), peak milk yield $(\mathbf{P M Y})$, and milk yield lactation persistency (LP) have been studied in the past in connection with health events (Muir et al., 2004; Appuhamy et al., 2009). However, nontrivial relationships might exist among health disorders and production traits (Heringstad et al., 2009). Inferring causal relationships between phenotypes could help disentangle the complex relationships between health disorders and production traits (Wu et al., 2008; Valente et al., 2010; Rehbein et al., 2013). In the context of animal breeding, Gianola and Sorensen (2004) extended quantitative genetic models to infer recursive and simultaneous relationships between phenotypes in a multivariate system. In recent years, structural equation models were applied to study recursive and simultaneous relationships among phenotypes in a multivariate system (Rosa et al., 2011).

Even though there is no mandatory or consistent recording of health disorders of dairy cows in the United States, previous studies by Zwald et al. (2004b), Appuhamy et al. (2009), and Parker Gaddis et al. (2014) have confirmed the possibility of using on-farm producer-recorded health information for genetic evaluation and to identify phenotypic relationships among health disorders. However, these previous studies have not explored the causal effect of health disorders on culling and production traits.

Causal relationships may exist between health disorders that evolve during the course of a cow's lactation. Identifying these causal relationships could help us better understand patterns of disease insurgence. Similarly, inferring the magnitude of causal effects between health disorders and culling could help improve management strategies. Finally, eliciting the magnitude of a causal effect from a health disorder (occurring in early lactation) to early- and late-lactation production measures could improve our understanding of both the immediate effect of a health disorder and the delayed effect on overall lactation yield. To determine the magnitude of these effects, separate analyses were conducted in the present study. Structural equation models were used to infer causal relationships among binary (i.e., metabolic and reproductive health disorders, culling) and continuous (i.e., production) traits, particularly from metabolic and reproductive health disorders to early- and late-lactation production measures and from metabolic and reproductive health disorders to culling.

\section{MATERIALS AND METHODS}

\section{Data Description}

Early-lactation production measures such as test-day milk yields were used to estimate the immediate effect of health disorders. Similarly, mid-lactation production measures such as PeakD and PMY, and late-lactation production measures such as LP were used to estimate the delayed effect of health disorders on production. Culling was considered to estimate the effect of health disorders on culling of cows.

The producer-recorded dairy herd records were available from Dairy Records Management Systems (DRMS; Raleigh, NC) in the "Format 6: Health" data exchange format (Animal Improvement Programs Laboratory, 2010) from 1996 through June 2013. Among health disorders, metabolic (i.e., KETO and both right- and left-sided DA) and reproductive (i.e., $\mathrm{RP}$ and METR) disorders were selected for analysis. Health disorders occurring in the early part of lactation, from date of calving to the first $30 \mathrm{~d}$ of lactation, were considered. This range was chosen because the majority $(92 \%)$ of health disorders considered in the current study occurred in the first $30 \mathrm{~d}$ of lactation. The mean $( \pm \mathrm{SD})$ day of lactation to occurrence was $2.3( \pm 1.1)$ d for RP, $9.1( \pm 1.4)$ d for KETO, 11.7 $( \pm 1.3) \mathrm{d}$ for METR, and $18.5( \pm 1.9) \mathrm{d}$ for DA. Zwald et al. (2004a) also found that the majority of producerrecorded health disorders occurred during the first 30 d of lactation. For each of the health disorders, if a health disorder for a cow was recorded within $30 \mathrm{~d}$ of lactation, a score of 1 (diseased) was assigned to the cow; otherwise 0 (healthy) was assigned. Repeated cases of the same disorder were ignored. Reproductive disorders (RP and METR) were further combined as an all-or-none trait to create a single measure (REPRO). Similarly, metabolic disorders (KETO and DA) were further combined as an all-or-none trait to provide a single measure (META). 
Health data were merged with test-day milk yields provided by DRMS in "Format 4: Lactation" data exchange format (Animal Improvement Programs Laboratory, 2006). The test-day milk yields recorded during the first $120 \mathrm{~d}$ of lactation were divided into $\sim 60$-d periods such that 6 to 60 DIM was categorized as period 1 and 61 to 120 DIM was categorized as period 2. For each cow, mean milk yield (MY) from test-day records after 5 DIM was obtained for each period, and referred to as MY1 and MY2 for periods 1 and 2, respectively. Because one of the main objectives of the paper was to determine the effect of health disorders on actual milk yield, cows with recorded calving but no test-day records $(\mathrm{n}=2,583)$ were included in the data set and assigned a MY of $0 \mathrm{~kg}$. The mid- and late-lactation production measures; that is, PeakD, PMY, and LP, were obtained for each cow starting from individual test-day yield using BESTPRED software (Cole and VanRaden, 2007). In this study, LP is defined as the ability of a cow to maintain milk production at a higher level after peak milk yield, which is independent of milk yield (Cole and VanRaden, 2006), and calculated as

$$
p=\sum_{i=1}^{n}\left(Y_{i}-S_{i}\right) \times\left(d_{i}-d_{0}\right)
$$

where $p$ is the persistency of milk yield of an individual lactation; $Y_{i}$ represents the $i$ th test-day milk yield; $S_{i}$ represents the $i$ th milk yield from the standard lactation curve on the $i$ th test-day; $d_{i}$ represents the DIM at $i$ th test-day; $d_{0}$ represents the reference DIM for milk; and $n$ represents the total number of test-day yield records used to calculate persistency. The standard lactation curve of milk yield was calculated by fitting Wood's curve to herd-average yields, and 128 DIM was used as $d_{0}$ for milk yield (Cole and VanRaden, 2006). Standardized estimates of persistency $(\hat{s})$ were obtained by subtracting the population mean for persistency $\left(\mu_{p}\right)$ divided by within-herd standard deviation of the persistency $p\left(S D_{p}\right)$ following Cole and VanRaden (2007):

$$
\hat{s}=\frac{\hat{p}-\mu_{p}}{S D_{p}} .
$$

Culling was scored as 1 if the termination code was 3 or 4 and if the cow had no test-day record after $\mathrm{d}$ 120, 0 otherwise. Incidence of culling was based on termination codes 3 and 4 of "Format 4: Lactation" data exchange format (Animal Improvement Programs Laboratory, 2006). Termination code 3 was defined as "Cow sold for poor production" and termination code 4 was defined as "Cow sold because of reproductive problems" (Animal Improvement Programs Laboratory, 2013); other termination codes were not included in the study because they were assigned to different health disorders such as locomotion problems, mastitis or high somatic cells, undesirable confirmation, aggressive behavior, and so on.

Health disorder data edits were applied as described in Parker Gaddis et al. (2012). After applying data quality edits, we found that only records of disorders from year 2011 and 2012 were of good quality; that is, all metabolic and reproductive health disorders were properly recorded by farmers, and thus were retained for analysis. In the data set, 77,004 first-parity Holsteins daughters from 2,183 sires across 553 herds were represented. There were 7,844 total individuals in the sirematernal grandsire pedigree. In this analysis, all cows were considered because removing culled cows from the data would cause bias due to sampling problems. This data set is hereafter referred to as Health-Culling-Prod. Within Health-Culling-Prod, the traits included were health disorders, culling, and MY.

To identify the causal effect of health disorders on middle and late production measures, a subset of Health-Culling-Prod was formed and termed the Health-Prod data set. Data editing constraints applied to Health-Prod were the same as that of Health-Culling-Prod except that only cows with test-day records in late lactation and having 305-d milk yield records were retained for analysis. Health-Prod included 67,907 firstparity records from 2,029 sires across 548 herds. The sire-maternal grandsire pedigree included 6,058 total individuals. Traits included in Health-Prod were health disorders, PeakD, PMY, and LP.

\section{Statistical Analyses}

A series of analyses was defined to meet the objectives of the study. To identify the causal relationship of health disorders and culling (using Health-CullingProd), a bivariate threshold-threshold sire recursive structural equation model was used and hereafter termed the Health-Culling analysis. The threshold model assumed an underlying continuous variable, liability $\left(y_{i}\right)$, for binary traits that defined the observed binary variable into a value of 1 if liability was larger than a fixed threshold and 0 otherwise. A causal effect of health disorder on culling was considered as shown in Figure 1. In total, 4 analyses were conducted on Health-Culling analyses, in which each health disorder were analyzed along with its specific culling trait.

Threshold-Gaussian structural equation models were used to elicit causal relationships among health disorders and milk yields (using Health-Culling-Prod). The recursive causal structure was, in this case, from one 


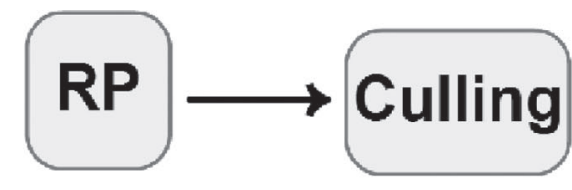

(A)

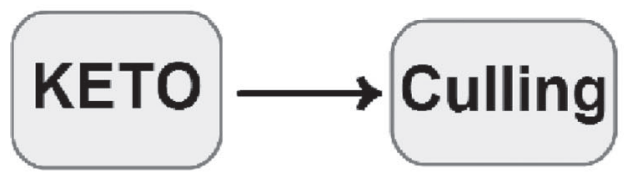

(C)

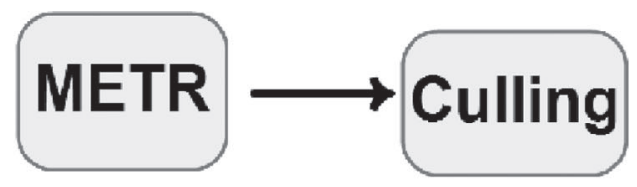

(B)

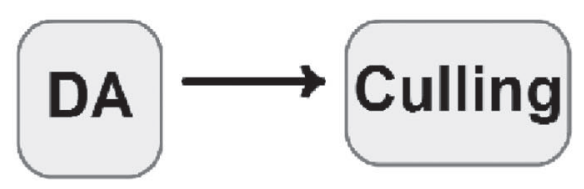

(D)

Figure 1. Causal structure assumption between health disorders and culling. A single-headed arrow $(\rightarrow)$ indicates a recursive effect, in which a health disorder has an effect on culling but not vice versa. $\mathrm{RP}=$ retained placenta; $\mathrm{METR}=$ metritis; KETO $=$ ketosis; $\mathrm{DA}=$ displaced abomasum.

health disorder to another health disorder and from health disorders to milk yields (MY1 and MY2), as shown in Figure 2. The one-way causal structure from one health disorder to another was considered based on time of occurrence of the disorder from calving date. This assumption was based on the study by Parker Gaddis et al. (2012), where they used path analysis to explore the putative relationships between one health disorder and another health disorder based on occurrence of health disorder after calving. According to this definition, a disorder that occurred closest to the calving date had an effect on a health event occurring later in a cow's lactation. Using the causal structure defined above, 3 analyses were performed and are termed Health-MY analyses hereafter. Each included 2 Gaussian traits, MY1 and MY2, and 2 health disorders - either RP and METR, KETO and DA, or REPRO and META - and direct and indirect recursive effects were assumed from the first trait to MY1 and MY2. For example, direct and indirect recursive effects were assumed from RP to MY1. The direct recursive effect measured how much MY1 would be affected by the change in liability to RP. The indirect recursive effect measured how much MY1 would be affected by change in liability to RP through the mediating effect of the liability to METR. The indirect recursive effect can be calculated as the product of structural coefficients (RP $\rightarrow$ METR) $\times($ METR $\rightarrow$ MY1) (Shipley, 2002; López de Maturana et al., 2009). The overall causal effect of $\mathrm{RP}$ on MY1 can then be calculated as (RP $\rightarrow$ MY1) + $[(\mathrm{RP} \rightarrow \mathrm{METR}) \times(\mathrm{METR} \rightarrow \mathrm{MY} 1)]$. For the REPRO and META health disorders, despite the fact that not all reproductive health disorders occurred before the metabolic health disorders in a cow's lactation, a causal effect was assumed between REPRO and META, with recursive effects from REPRO to META.
A threshold-Gaussian structural equation model was used to explore the causal relationships between health disorders and production parameters describing the lactation curve, such as PeakD, PMY, and LP (using Health-Prod). Again, a one-way causal structure was considered between health disorders and production traits (PeakD, PMY, and LP) as shown in Figure 3, and 4 analyses were performed using this causal structure. These analyses are termed Health-Lactation hereafter. Each included 3 Gaussian traits (PeakD, PMY, and LP) and 1 binary health disorder trait: RP, METR, KETO, or DA.

The equations used in the above analyses can be represented as follows:

$$
\begin{aligned}
& \text { Health-Culling: }\left\{\begin{array}{l}
\mathbf{y}_{1}=\mathbf{X} \mathbf{b}_{1}+\mathbf{Z}_{\mathbf{h}} \mathbf{h}_{1}+\mathbf{Z}_{\mathbf{s}} \mathbf{s}_{1}+\mathbf{e}_{1} \\
\mathbf{y}_{2}=\lambda_{21} \mathbf{y}_{1}+\mathbf{X} \mathbf{b}_{2}+\mathbf{Z}_{\mathbf{h}} \mathbf{h}_{2}+\mathbf{Z}_{\mathbf{s}} \mathbf{s}_{2}+\mathbf{e}_{2}
\end{array}\right. \\
& \text { Health-MY: }\left\{\begin{array}{l}
\mathbf{y}_{1}=\mathbf{X} \mathbf{b}_{1}+\mathbf{Z}_{\mathbf{h}} \mathbf{h}_{1}+\mathbf{Z}_{\mathbf{s}} \mathbf{s}_{1}+\mathbf{e}_{1} \\
\mathbf{y}_{2}=\lambda_{21} \mathbf{y}_{1}+\mathbf{X} \mathbf{b}_{2}+\mathbf{Z}_{\mathbf{h}} \mathbf{h}_{2}+\mathbf{Z}_{\mathbf{s}} \mathbf{s}_{2}+\mathbf{e}_{2} \\
\mathbf{y}_{3}=\lambda_{31} \mathbf{y}_{1}+\lambda_{32} \mathbf{y}_{2}+\mathbf{X} \mathbf{b}_{3}+\mathbf{Z}_{\mathbf{h}} \mathbf{h}_{3}+\mathbf{Z}_{\mathbf{s}} \mathbf{s}_{3}+\mathbf{e}_{3} \\
\mathbf{y}_{4}=\lambda_{41} \mathbf{y}_{1}+\lambda_{42} \mathbf{y}_{2}+\mathbf{X} \mathbf{b}_{4}+\mathbf{Z}_{\mathbf{h}} \mathbf{h}_{4}+\mathbf{Z}_{\mathbf{s}} \mathbf{s}_{4}+\mathbf{e}_{4}
\end{array}\right. \\
& \text { Health-Lactation: }\left\{\begin{array}{l}
\mathbf{y}_{1}=\mathbf{X} \mathbf{b}_{1}+\mathbf{Z}_{\mathbf{h}} \mathbf{h}_{1}+\mathbf{Z}_{\mathbf{s}} \mathbf{s}_{1}+\mathbf{e}_{1} \\
\mathbf{y}_{2}=\lambda_{21} \mathbf{y}_{1}+\mathbf{X} \mathbf{b}_{2}+\mathbf{Z}_{\mathbf{h}} \mathbf{h}_{2}+\mathbf{Z}_{\mathbf{s}} \mathbf{s}_{2}+\mathbf{e}_{2} \\
\mathbf{y}_{3}=\lambda_{31} \mathbf{y}_{1}+\mathbf{X} \mathbf{b}_{3}+\mathbf{Z}_{\mathbf{h}} \mathbf{h}_{3}+\mathbf{Z}_{\mathbf{s}} \mathbf{s}_{3}+\mathbf{e}_{3} \\
\mathbf{y}_{4}=\lambda_{41} \mathbf{y}_{1}+\mathbf{X} \mathbf{b}_{4}+\mathbf{Z}_{\mathbf{h}} \mathbf{h}_{4}+\mathbf{Z}_{\mathbf{s}} \mathbf{s}_{4}+\mathbf{e}_{4}
\end{array}\right.
\end{aligned}
$$

In the equations above, $\mathbf{y}_{1}$ and $\mathbf{y}_{2}$ are the vectors of liability to health disorder and liability to culling in Health-Culling analyses, respectively; $\mathbf{y}_{1}$ and $\mathbf{y}_{2}$ are the vectors of liability to health disorder, and $\mathbf{y}_{3}$ and $\mathbf{y}_{4}$ are the vectors of observations of milk yields (health disor- 
A

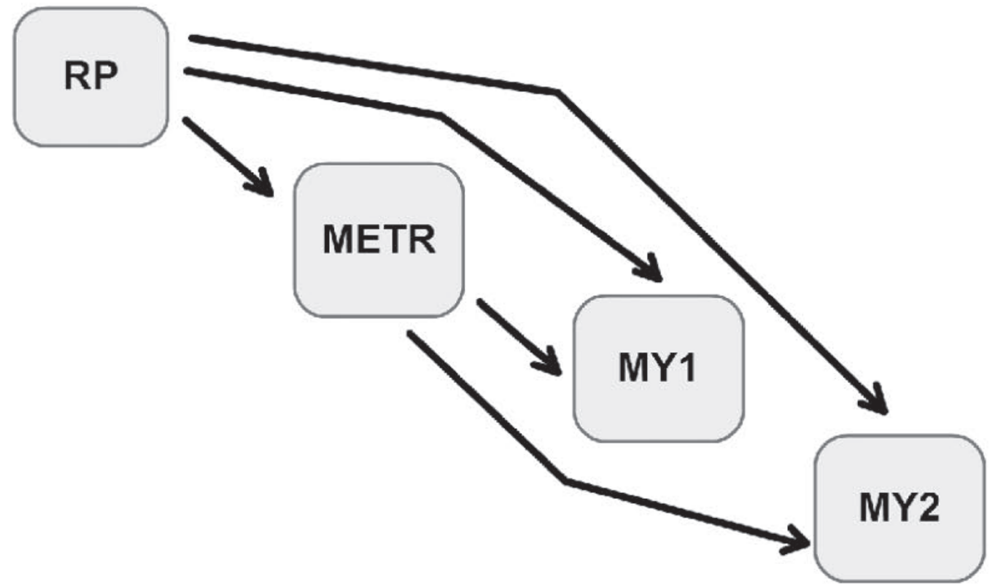

B

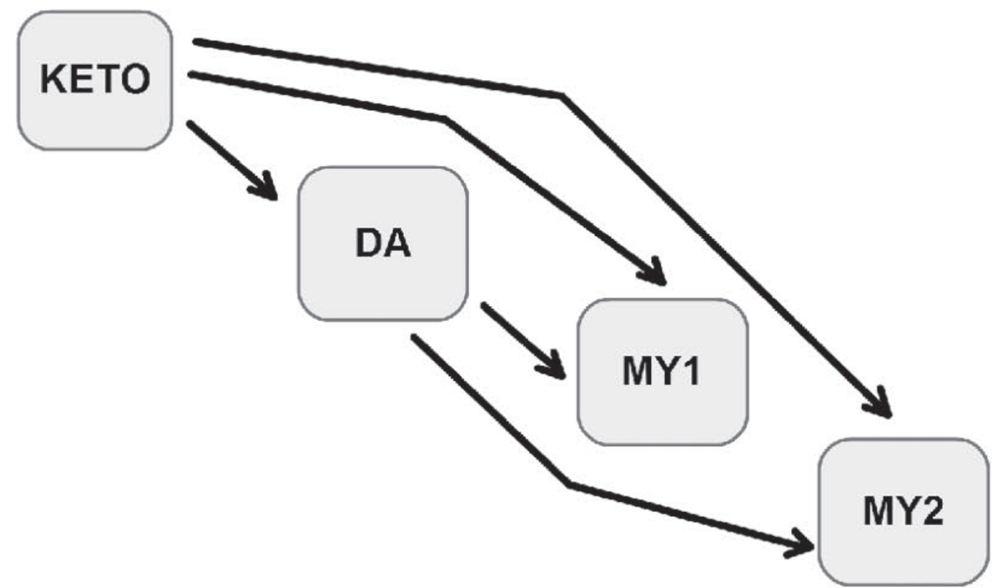

C

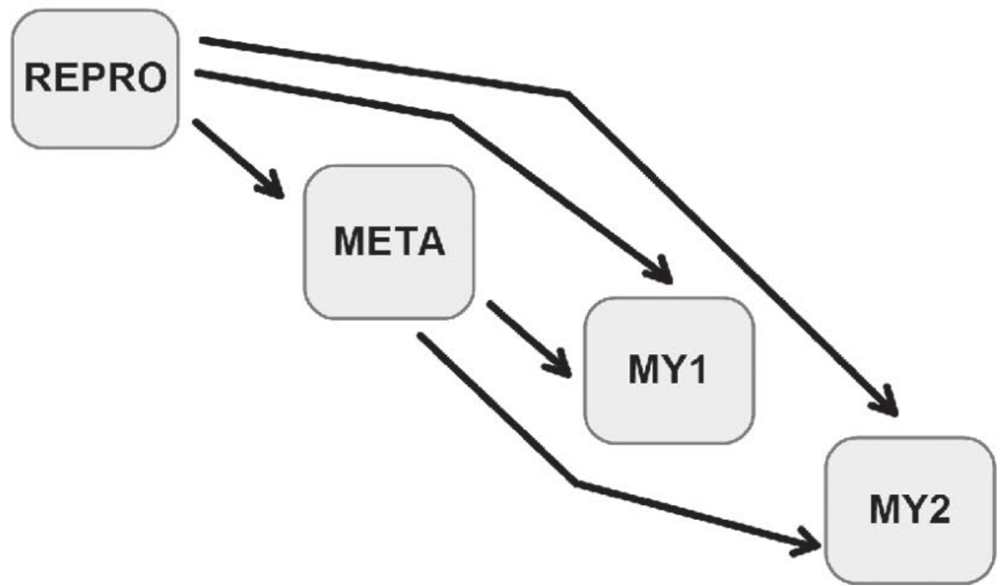

Figure 2. Recursive effects between one health disorder to another, and from health disorders to MY1 and MY2. A single-headed arrow $(\rightarrow$ ) indicates the direction of the causal relationship between (A) RP, METR, MY1, and MY2 traits, (B) KETO, DA, MY1, and MY2 traits, and (C) REPRO, META, MY1, and MY2 traits. RP = retained placenta; METR = metritis; MY1 and MY2 = mean milk yields obtained from test-day records from 5 to 60 DIM and from 61 to 120 DIM, respectively; KETO = ketosis; DA = displaced abomasum; REPRO = reproductive diseases; META = metabolic diseases. 


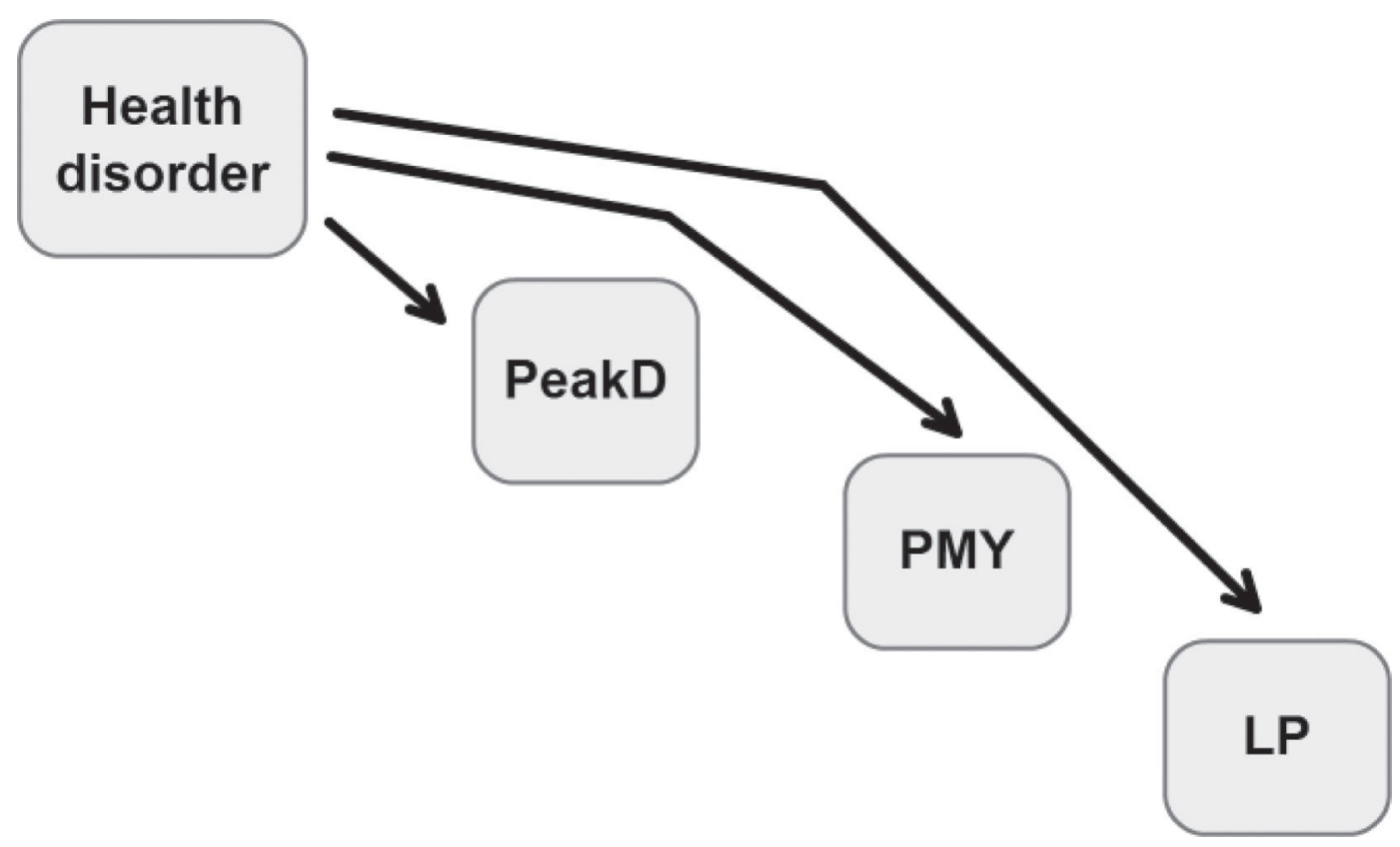

Figure 3. Recursive effects from health disorders to production measures such as DIM at peak milk yield (PeakD), peak milk yield (PMY), and lactation persistency of milk yield (LP). This model was used for each of the 4 health disorders: (retained placenta, metritis, ketosis, displaced abomasum). A single-headed arrow $(\rightarrow)$ indicates a causal relationship.

der 1, health disorder 2, MY1 and MY2, considered in this order) in Health-MY analyses; and $\mathbf{y}_{1}$ is the vector of liability to health disorder, and $\mathbf{y}_{2}, \mathbf{y}_{3}$, and $\mathbf{y}_{4}$ are the vectors of observations of production traits (health disorder, PeakD, PMY, and LP, considered in this order) for the Health-Lactation analyses. For all models, $\lambda_{\mathrm{ij}}$ represents the structural coefficients describing the rate of change of trait $i$ with respect to trait $j$. For Health-Culling analyses, $\lambda_{21}$ is the response of liability to culling with respect to liability to health disorders. For Health-MY, for example, in the analysis including RP, METR, MY1, and MY2 traits, $\lambda_{21}$ is the response of liability to METR with respect to liability to RP. The rate of change in MY1 with respect to liability to RP and liability to METR are given by $\lambda_{31}$ and $\lambda_{32}$. Similarly, the rate of change in MY2 with respect to liability to RP and liability to METR are given by $\lambda_{41}$ and $\lambda_{42}$. For Health-Lactation analyses, the structural coefficients $\lambda_{\mathrm{ij}}$ describe, for example, the rate of change in PeakD with respect to RP given by $\lambda_{21}$. For all models, $\mathbf{b}$ is a vector of systematic effects including the effect of year-season of calving; $\mathbf{h}$ is a vector of herd effects, $\mathbf{s}$ is a vector of sire effects, and $\mathbf{e}$ is a vector of residuals; $\mathbf{X}, \mathbf{Z}_{\mathrm{h}}$, and $\mathbf{Z}_{\mathrm{s}}$ are the corresponding incidence matrices.

In matrix form, the general model for all 3 different analyses can be written as

$$
\mathbf{y}=(\mathbf{\Lambda} \otimes \mathbf{I}) \mathbf{y}+\mathbf{X b}+\mathbf{Z}_{\mathbf{h}} \mathbf{h}+\mathbf{Z}_{\mathbf{s}} \mathbf{s}+\mathbf{e},
$$

where the $\boldsymbol{\Lambda}$ matrix of structural effects for 3 different analyses can be written as follows:

$$
\begin{gathered}
\text { Health-Culling: } \Lambda_{1}=\left[\begin{array}{cc}
0 & 0 \\
\lambda_{21} & 0
\end{array}\right], \\
\text { Health-MY: } \Lambda_{2}=\left[\begin{array}{cccc}
0 & 0 & 0 & 0 \\
\lambda_{21} & 0 & 0 & 0 \\
\lambda_{31} & \lambda_{32} & 0 & 0 \\
\lambda_{41} & \lambda_{42} & 0 & 0
\end{array}\right], \\
\text { Health-Lactation: } \Lambda_{3}=\left[\begin{array}{cccc}
0 & 0 & 0 & 0 \\
\lambda_{21} & 0 & 0 & 0 \\
\lambda_{31} & 0 & 0 & 0 \\
\lambda_{41} & 0 & 0 & 0
\end{array}\right] .
\end{gathered}
$$

Prior distributions for structural coefficients, systematic effects $\mathbf{b}$, sire genetic effects $\mathbf{s}$, effect of herd $\mathbf{h}$, and the corresponding (co)variance matrices were similar to those described by Heringstad et al. (2009). Structural coefficients were assumed a multivariate normal prior distributions as $N\left(\mathbf{1} \lambda_{0}, \mathbf{I} \tau^{2}\right)$, where hyperparameters were $\lambda_{0}=0$ and $\tau^{2}=10,000$. Elements of $\mathbf{b}$ were assigned normal prior distributions, with mean 0 and variance 10,000. Sire effects were assigned a multivariate normal prior distribution $\mathbf{s} \sim N(\mathbf{0}, \mathbf{G} \otimes \mathbf{A})$, where 
$\mathbf{G}$ is the sire covariance matrix for the traits involved and $\mathbf{A}$ is the matrix of additive genetic relationships among sires. The prior distribution of the herd effects was $\mathbf{h} \sim N(\mathbf{0}, \mathbf{H} \otimes \mathbf{I}$ ), where $\mathbf{H}$ is the (co)variance matrix and $\mathbf{I}$ is an identity matrix. Prior distributions for covariance matrices $\mathbf{G}$, and $\mathbf{H}$, were independent inverse-Wishart invWish $(\boldsymbol{\nu}, \mathbf{S})$, where $\boldsymbol{\nu}$ are the degrees of freedom and $\mathbf{S}$ is the scale. Residual variances were fixed to 1 and residual covariances were assumed equal to 0 . This assumption is required for the identifiability of structural coefficients and reflects causal assumption where all the variables (e.g., sire additive genetic effect, cow permanent environmental, herd environmental effects) that are common causes of 2 or more phenotypic traits are assumed to be accounted in the model, so that it supports causal interpretation of structural coefficients (Pearl, 2000; Spirtes et al., 2000). In this case, prior distribution for $\mathbf{R}$ was an inverse-Wishart distribution, conditional on all binary characters having unit residual variances (Korsgaard et al., 2003). The estimated covariance matrices for models from each series of analyses were transformed into multiple trait model scale as

$$
\begin{aligned}
& \mathbf{G}_{n}^{*}=(\mathbf{I}-\boldsymbol{\Lambda})_{n}^{-1} \mathbf{G}_{n}(\mathbf{I}-\boldsymbol{\Lambda})_{n}^{\prime-1}, \\
& \mathbf{H}_{n}^{*}=(\mathbf{I}-\boldsymbol{\Lambda})_{n}^{-1} \mathbf{H}_{n}(\mathbf{I}-\boldsymbol{\Lambda})_{n}^{\prime-1}, \\
& \mathbf{R}_{n}^{*}=(\mathbf{I}-\boldsymbol{\Lambda})_{n}^{-1} \mathbf{R}_{n}(\mathbf{I}-\boldsymbol{\Lambda})_{n}^{\prime-1},
\end{aligned}
$$

where the index $n$ indicates the models used for HealthCulling, Health-MY, and Health-Lactation analyses; $\mathbf{G}, \mathbf{H}, \mathbf{R}$, and $\boldsymbol{\Lambda}$ are as defined above, and $\mathbf{I}$ is the identity matrix. This transformation was performed mainly because interpretation of system parameters obtained from the structural equation model is different from that of the analogous parameters from the multiple trait model. Heritabilities and genetic correlations were then calculated in the usual manner from (co) variance components in $\mathbf{G}_{n}^{*}, \mathbf{H}_{n}^{*}$, and $\mathbf{R}_{n}^{*}$.

Data analyses were conducted in a Bayesian framework using the SIR-BAYES package (Wu et al., 2007, 2008), in which all Bayesian models were implemented via Markov chain Monte Carlo methods. For each model, 100,000 iterations were run and posterior samples from each chain were thinned every 25 iterations after 20,000 iterations of burn-in. Posterior distributions of parameters of interest were inferred based on posterior samples after burn-in and thinning. Markov chain convergence was assessed by visual inspection of trace plots; in addition, Geweke's convergence statistic (Geweke, 1992) was obtained through the CODA package (Plummer et al., 2013) of R (http://cran.r-project.org).

For ease of interpretation, estimates on the liability scale were converted to the observable scale following $\mathrm{Wu}$ et al. (2008). For example, the difference in the mean PMY between sick (1) cows due to RP and healthy $(0)$ cows can be calculated as $\Delta \approx \lambda\left(\overline{l_{1}}-\overline{l_{0}}\right)$, where $\bar{l}_{1}$ and $\bar{l}_{0}$ are averages of increased liabilities for sick cows due to RP and healthy cows, respectively, and lambda $(\lambda)$ is as defined above.

\section{RESULTS AND DISCUSSION}

Summary statistics of metabolic and reproductive health disorders along with the culling following each health event of interest are shown in Table 1. The largest incidence of health disorder was for METR followed by RP and KETO. The lowest incidences were observed for DA. Studies (Zwald et al., 2004b; Parker Gaddis et al., 2012) have reported that fewer discrepancies in diagnosis were found for DA, because veterinarian intervention was required most of the time in DA cases, making DA reporting consistent across herds. Even though the incidence of DA observed in this study was low, the reporting of DA may be more accurate, making the interpretation of results more reliable. Summary statistics of production traits are shown in Table 2 . Mean peak milk yield was $36.41 \mathrm{~kg}$, which was slightly higher than that reported by Muir et al. (2004; 31.35 $\mathrm{kg}$ ) for first-lactation Canadian Holsteins.

\section{Recursive Effects: Health Disorders and Culling}

Structural coefficients $\lambda$ measure recursiveness at the phenotypic level (Gianola and Sorensen, 2004). Posterior distribution of recursive effects from liability of health disorders to liability to culling are shown in Figure 4A, and their posterior mean, standard deviation (SD), and 95\% highest posterior density interval $(\mathbf{9 5 \%}$ HPD) are shown in Table 3. Posterior means of recursive effects from health disorders to culling were positive and ranged from 0.93 to 1.59 on the liability scale. The SD of the structural coefficients were moderate, ranging from 0.05 to 0.11 . The $95 \%$ HPD did not include zero for any of the analyses with traits involving liability to health disorders and culling. The recursive effects indicate that each 1-unit increase of liability for RP, METR, KETO and DA would increase culling by $1.23,0.93,1$, and 1.59 on the underlying liability scale, respectively. On the observable scale, the difference in mean culling between sick (due to RP, METR, KETO, and DA) and healthy cows is $3.48,2.68,3.99$, and 7.85 percentage units, respectively. In general, strong causal 
Table 1. Descriptive statistics for metabolic (ketosis and displaced abomasum) and reproductive (retained placenta and metritis) health disorders

\begin{tabular}{|c|c|c|c|c|c|}
\hline \multirow[b]{2}{*}{ Trait } & \multicolumn{2}{|c|}{ No. of records } & \multirow{2}{*}{$\begin{array}{l}\text { Health disorder } \\
\text { frequency }(\%)\end{array}$} & \multirow{2}{*}{$\begin{array}{l}\text { Culling risk for } \\
\text { diseased cows }\end{array}$} & \multirow{2}{*}{$\begin{array}{l}\text { Culling risk for } \\
\text { healthy cows }\end{array}$} \\
\hline & Healthy & Diseased & & & \\
\hline Retained placenta & 75,245 & 1,759 & 2.28 & 5.00 & 0.80 \\
\hline Metritis & 73,578 & 3,426 & 4.45 & 6.65 & 1.30 \\
\hline Ketosis & 75,716 & 1,288 & 1.67 & 8.15 & 1.05 \\
\hline Displaced abomasum & 76,821 & 183 & 0.24 & 7.65 & 0.30 \\
\hline
\end{tabular}

${ }^{1}$ Percentage of diseased cows culled during first lactation following health disorders.

${ }^{2}$ Percentage of healthy cows culled during first $120 \mathrm{~d}$ in milk.

relationships were identified between health disorders and culling.

Gröhn et al. (1998) reported the disease-specific risk of culling for Holstein cows: $26.9 \%$ for DA, $32.5 \%$ for KETO, $31.7 \%$ for RP, and $17.1 \%$ for METR across lactations compared with culling risk of healthy cows. The recursive effects obtained in our results suggest a similar trend for culling cows. Raizman et al. (2002) conducted a survival analysis and found that $8 \%$ of cows died and $27.7 \%$ of cows were sold out of 188 cows affected with DA. The structural coefficient for liability to DA to culling in our analysis indicates that cows affected with DA have higher culling risk. Similarly, Lewis (1997) reported that cows with METR had higher culling (26.6\%) compared with cows without METR (20.5\%). The posterior mean of recursive effect from METR to culling from our study suggests that an increase in incidence of METR would directly increase the culling by 2.68 percentage units. Cobo-Abreu et al. (1979) reported an odds ratio (OR) of 4.1 for METR and risk of culling and an OR of 2.3 for RP and risk of culling. Bigras-Poulin (1985) reported an OR of 1.8 for $\mathrm{RP}$ and risk of culling. Oltenacu et al. (1990) reported an OR of 1.4 for RP and risk of culling and an OR of 0.8 for KETO and risk of culling. The OR for disease and risk of culling mentioned above is a measure of association between disease exposure and culling outcome and does not account for the causal relationships between traits. The causal effect from diseases to culling found in our study is strong proof of the causal relationships between diseases and culling.

\section{Health Disorders and Production Traits}

Recursive effects obtained from the Health-MY analyses are given in Table 4. Posterior distributions of recursive effects (on the liability scale) of one health disorder on a second disorder are shown in Figure 4B, and recursive effects of health disorders on yield traits MY1 and MY2 are shown in Figure 4C, D, E, and F. Recursive effects were detected from one health disorder to another health disorder (Table 4). In contrast, recursive effects were not detected from health disorders to MY1 and MY2, because the 95\% HPD of structural coefficients of liability to health disorder to MY included zero in their credible region, except for the structural coefficient obtained for liability to METR to MY2 (Table 4). We can infer that these health disorders did not affect the actual production of the cow. Results showed a positive recursive effect from liability to RP on liability to METR (approximately 0.120 units increase of liability to METR for a 1-unit increase of liability to RP). The posterior means of the recursive effect of METR on MY2 was $0.085 \mathrm{~kg}$ per unit of increased liability of METR. For metabolic diseases, the results showed a positive effect from KETO to DA with a posterior mean of the direct recursive effect of 0.122 . The direct recursive effects from liability to KETO to

Table 2. Descriptive statistics of production traits

\begin{tabular}{|c|c|c|c|c|c|}
\hline Traits & $\begin{array}{l}\text { No. of } \\
\text { records }\end{array}$ & Mean & SD & Minimum & Maximum \\
\hline Milk yield $1^{1}(\mathrm{~kg})$ & 77,004 & 30.05 & 8.50 & 0 & 57.16 \\
\hline Milk yield $2^{2}(\mathrm{~kg})$ & 77,004 & 28.65 & 13.78 & 0 & 69.17 \\
\hline Peak milk yield $(\mathrm{kg})$ & 67,907 & 36.41 & 5.52 & 13.38 & 68.36 \\
\hline DIM of peak milk yield $(\mathrm{d})$ & 67,907 & 55.27 & 20.05 & 30 & 145 \\
\hline Lactation persistency $^{3}$ & 67,907 & 0.47 & 0.98 & -5.31 & 5.49 \\
\hline
\end{tabular}


(A)

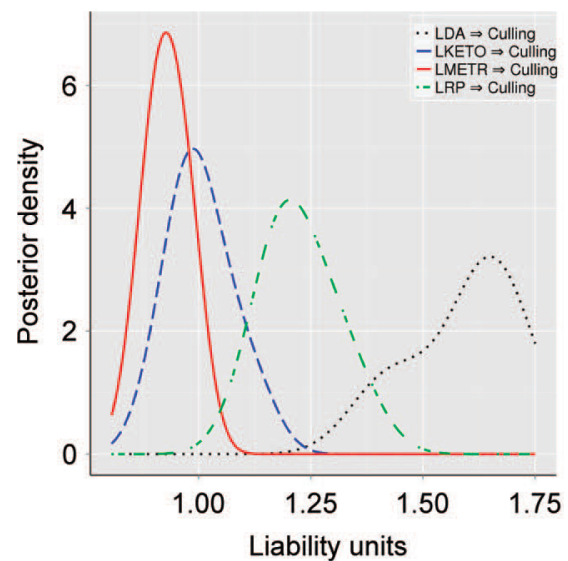

(D)

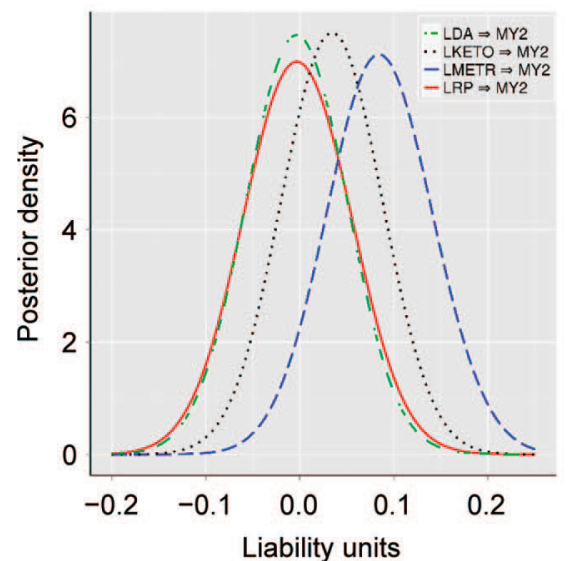

(B)

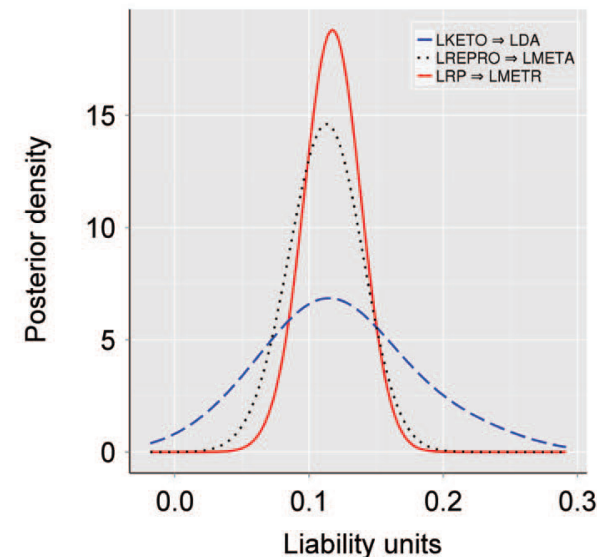

(E)

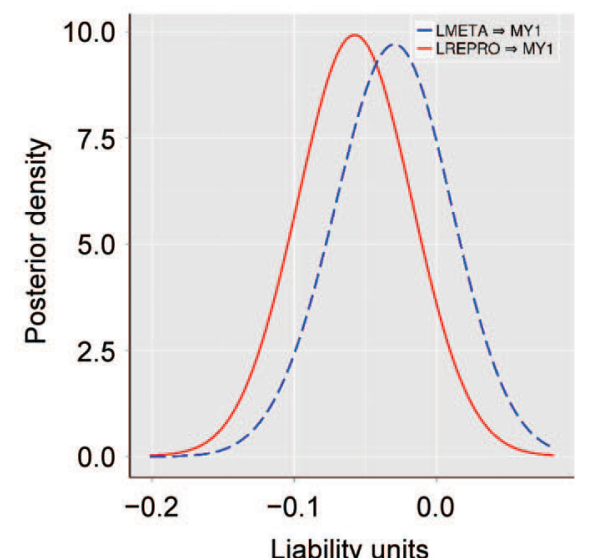

(C)

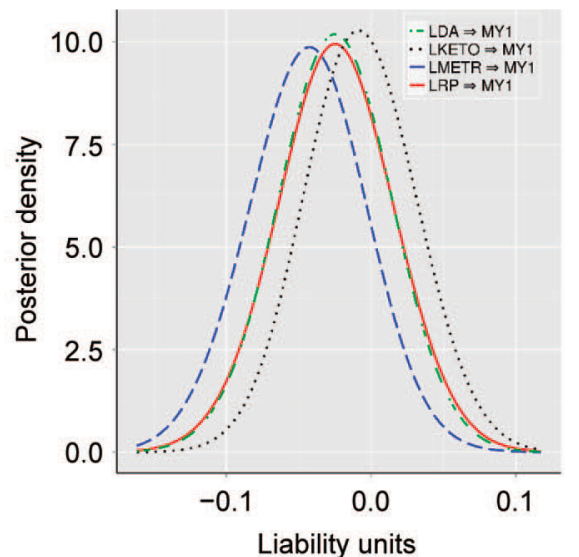

(F)

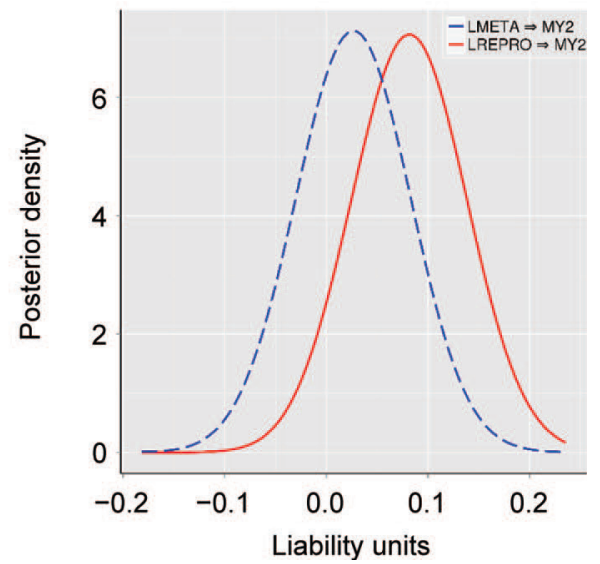

Figure 4. Posterior distributions of recursive effects (A) from liability (L) to health disorder (LDA, LKETO, LMETR, or LRP) to liability of culling; (B) from liability to one health disorder (LKETO, LRP, and LREPRO) to liability to another health disorder (LDA, LMETR, and LMETA); (C) from liability to health disorders (LDA, LKETO, LMETR, LRP) to milk yield 1 (MY1); (D) from liability to health disorders (LDA, LKETO, LMETR, LRP) to milk yield 2 (MY2); (E) from liability to health disorders (LREPRO, LMETA) to MY1; (F) from liability to health disorders (LREPRO, LMETA) to MY2. DA = displaced abomasum; KETO = ketosis; $\mathrm{METR}=$ metritis; RP = retained placenta; REPRO = reproductive diseases; META = metabolic diseases; MY1 and MY2 = mean milk yields obtained from test-day records from 5 to 60 DIM and from 61 to 120 DIM, respectively. Color version available online. 
Table 3. Posterior mean, standard deviation, and 95\% highest posterior density interval (95\% HPD) of phenotypic recursive effects from liability to health disorder [retained placenta $(\mathrm{RP})$, metritis (METR), ketosis (KETO), and displaced abomasum (DA)] to liability of culling from Health-Culling analyses

\begin{tabular}{lccc}
\hline & \multicolumn{3}{c}{ Recursive effects } \\
\cline { 2 - 4 } Trait $^{1}$ & Mean & SD & $95 \%$ HPD \\
\hline $\mathrm{RP} \rightarrow$ Culling & 1.226 & 0.078 & {$[1.091 ; 1.385]$} \\
$\mathrm{METR} \rightarrow$ Culling & 0.929 & 0.045 & {$[0.846 ; 1.018]$} \\
$\mathrm{KETO} \rightarrow$ Culling & 1.004 & 0.067 & {$[0.889 ; 1.145]$} \\
$\mathrm{DA} \rightarrow$ Culling & 1.590 & 0.110 & {$[1.379 ; 1.729]$} \\
\hline
\end{tabular}

${ }^{1} \mathrm{~A}$ single-headed arrow $(\rightarrow)$ indicates a causal relationship between traits listed, where the first trait affects the second trait.

MY1 and MY2 were negligible. Similarly, the indirect recursive effects from liability to KETO to MY1 and MY2 through the mediating effect of liability to DA were also negligible. The recursive effect of REPRO on META was positive (approximately 0.112 unit increase of liability to META for a 1-unit increase of liability to REPRO).

The recursive effects detected in the Health-MY analyses were converted to the observable scale. The difference in METR incidence between cows with and without RP was $0.34 \%$. Similarly, the difference in MY2 between cows with and without METR was 0.25 $\mathrm{kg}$. The difference in DA incidence between cows with and without KETO was $0.63 \%$. Likewise, the difference

Table 4. Posterior mean, standard deviation, and 95\% highest posterior density interval (95\% HPD) of phenotypic recursive effects between liability to health disorders [(retained placenta (RP), metritis (METR), ketosis (KETO), displaced abomasum (DA), metabolic (META), and reproductive (REPRO)] to production traits from the Health-Milk Yield (MY) analyses

\begin{tabular}{|c|c|c|c|}
\hline \multirow[b]{2}{*}{ Trait $^{1}$} & \multicolumn{3}{|c|}{ Recursive effects } \\
\hline & Mean & $\mathrm{SD}$ & $95 \% \mathrm{HPD}$ \\
\hline $\mathrm{RP} \rightarrow \mathrm{METR}$ & 0.117 & 0.017 & {$[0.084 ; 0.152]$} \\
\hline $\mathrm{RP} \rightarrow \mathrm{MY} 1$ & -0.025 & 0.033 & {$[-0.092 ; 0.040]$} \\
\hline $\mathrm{RP} \rightarrow \mathrm{MY} 2$ & -0.002 & 0.046 & {$[-0.092 ; 0.086]$} \\
\hline METR $\rightarrow$ MY1 & -0.044 & 0.033 & {$[-0.109 ; 0.019]$} \\
\hline $\mathrm{METR} \rightarrow \mathrm{MY} 2$ & 0.085 & 0.046 & {$[0.001 ; 0.178]$} \\
\hline $\mathrm{KETO} \rightarrow \mathrm{DA}$ & 0.122 & 0.051 & {$[0.022 ; 0.228]$} \\
\hline $\mathrm{KETO} \rightarrow$ MY1 & -0.007 & 0.031 & {$[-0.069 ; 0.051]$} \\
\hline $\mathrm{KETO} \rightarrow \mathrm{MY} 2$ & 0.034 & 0.043 & {$[-0.046 ; 0.117]$} \\
\hline $\mathrm{DA} \rightarrow \mathrm{MY} 1$ & -0.025 & 0.032 & {$[-0.086 ; 0.040]$} \\
\hline $\mathrm{DA} \rightarrow \mathrm{MY} 2$ & -0.003 & 0.043 & {$[-0.085 ; 0.082]$} \\
\hline $\mathrm{REPRO} \rightarrow \mathrm{META}$ & 0.112 & 0.022 & {$[0.071 ; 0.156]$} \\
\hline $\mathrm{REPRO} \rightarrow \mathrm{MY} 1$ & -0.058 & 0.033 & {$[-0.122 ; 0.004]$} \\
\hline $\mathrm{REPRO} \rightarrow \mathrm{MY} 2$ & 0.082 & 0.046 & {$[-0.007 ; 0.168]$} \\
\hline META $\rightarrow$ MY1 & -0.031 & 0.034 & {$[-0.098 ; 0.034]$} \\
\hline $\mathrm{META} \rightarrow \mathrm{MY} 2$ & 0.026 & 0.045 & {$[-0.065 ; 0.111]$} \\
\hline
\end{tabular}

${ }^{1} \mathrm{~A}$ single-headed arrow $(\rightarrow)$ indicates a causal relationship between traits listed, where the first trait affects the second trait. MY1 and MY2 = mean milk yields obtained from test-day records from 5 to 60 DIM and from 61 to 120 DIM, respectively. in META incidence between cows with and without REPRO was $0.29 \%$.

The magnitude of causal effects from one health disorder to another health disorder in META, REPRO, or the combined (reproductive and metabolic) category was moderate (Table 4). Posterior means of inferred structural coefficients indicate that the occurrence of one health disorder would directly increase the liability to other health disorders. Recursive effects were not detected between health disorders and the production traits MY1 and MY2. Explanations for this are as follows: (1) there might be no recursive effect present between health disorders and milk yields (MY1, and MY2), or (2) both of these traits might be regulated by third trait such as negative energy balance, which may not produce a direct link between health disorders and milk yields (MY1 and MY2).

Recursive effects obtained from Health-Lactation analyses (which included health disorders and production parameters describing the overall lactation curve using Health-Prod) are given in Table 5 and the posterior distributions are shown in Figure 5. The 95\% HPD of all structural coefficients of liability of health disorders to production traits (PeakD, PMY, and LP) included zero in their credible interval, thus the interpretation of causal effects should be considered carefully. Possible explanations for this behavior might be that the causal effect of health disorders on production traits could be null or of relatively small magnitude or that these results might be due to the use

Table 5. Posterior mean, standard deviation, and $95 \%$ highest posterior density interval (95\% HPD) of phenotypic recursive effects from liability to health disorders [(retained placenta $(\mathrm{RP})$, metritis (METR), ketosis (KETO), and displaced abomasum (DA)] to production traits [DIM of peak milk yield (PeakD), peak milk yield (PMY), lactation persistency (LP)] from Health-Lactation analyses

\begin{tabular}{lrcc}
\hline & \multicolumn{3}{c}{ Recursive effects } \\
\cline { 2 - 4 } Trait $^{1}$ & Mean & SD & $95 \%$ HPD \\
\hline $\mathrm{RP} \rightarrow$ PeakD & 0.095 & 0.146 & {$[-0.177 ; 0.390]$} \\
$\mathrm{RP} \rightarrow$ PMY & -0.011 & 0.038 & {$[-0.084 ; 0.065]$} \\
$\mathrm{RP} \rightarrow$ LP & -0.001 & 0.033 & {$[-0.064 ; 0.062]$} \\
$\mathrm{METR} \rightarrow$ PeakD & 0.026 & 0.149 & {$[-0.281 ; 0.295]$} \\
$\mathrm{METR} \rightarrow$ PMY & -0.001 & 0.038 & {$[-0.072 ; 0.077]$} \\
$\mathrm{METR} \rightarrow$ LP & 0.001 & 0.033 & {$[-0.065 ; 0.063]$} \\
KETO $\rightarrow$ PeakD & 0.020 & 0.145 & {$[-0.237 ; 0.318]$} \\
KETO $\rightarrow$ PMY & -0.012 & 0.037 & {$[-0.082 ; 0.063]$} \\
KETO $\rightarrow$ LP & -0.002 & 0.033 & {$[-0.062 ; 0.062]$} \\
$\mathrm{DA} \rightarrow$ PeakD & 0.018 & 0.145 & {$[-0.257 ; 0.297]$} \\
$\mathrm{DA} \rightarrow$ PMY & 0.003 & 0.037 & {$[-0.064 ; 0.078]$} \\
$\mathrm{DA} \rightarrow$ LP & 0.001 & 0.032 & {$[-0.060 ; 0.062]$} \\
\hline $\mathrm{A}$ &
\end{tabular}

${ }^{1} \mathrm{~A}$ single headed arrow $(\rightarrow)$ indicates a causal relationship between traits listed, where the first trait affects the second trait. Lactation persistency (LP) is defined as the ability of a cow to maintain milk production at a higher level after peak milk yield, which is independent of milk yield. 
(A)

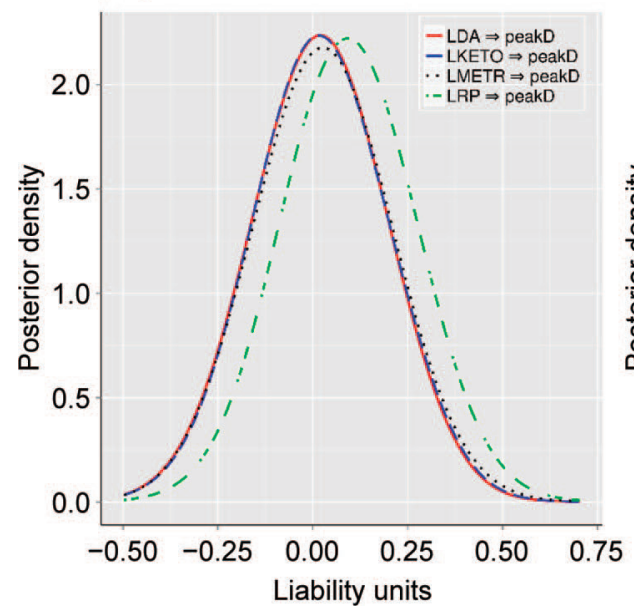

(B)

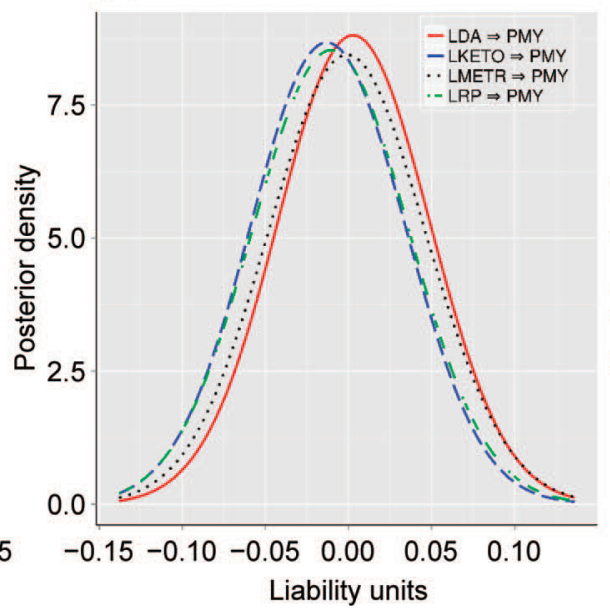

(C)

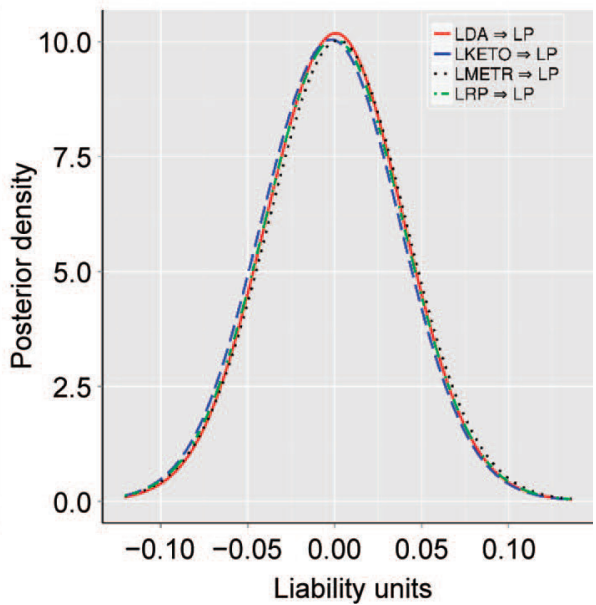

Figure 5. Posterior distributions of recursive effects (A) from liability (L) to health disorders (LDA, LKETO, LMETR, or LRP) to DIM of peak milk yield (PeakD); (B) from liability to health disorders to peak milk yield (PMY); (C) from liability to health disorders to lactation persistency. $\mathrm{DA}=$ displaced abomasum; KETO = ketosis; $\mathrm{METR}=$ metritis; $\mathrm{RP}=$ retained placenta. Color version available online.

Table 6. Posterior mean, standard deviation, and $95 \%$ highest posterior density interval (95\% HPD) of heritability of liability to health disorders and production traits from Health-Culling, Health-Milk Yield (MY), and Health-Lactation analyses

\begin{tabular}{llccc}
\hline & & \multicolumn{3}{c}{ Heritability $^{1}$} \\
\cline { 3 - 5 } Analysis & Trait & Mean & SD & $95 \%$ HPD \\
\hline Health-Culling & Displaced abomasum & 0.10 & 0.04 & {$[0.015 ; 0.147]$} \\
& Ketosis & 0.04 & 0.01 & {$[0.016 ; 0.065]$} \\
& Metritis & 0.02 & 0.01 & {$[0.010 ; 0.037]$} \\
& Retained placenta & 0.05 & 0.01 & {$[0.021 ; 0.070]$} \\
Culling & & 0.06 & 0.03 & {$[0.012 ; 0.136]$} \\
Health-MY & Displaced abomasum & 0.11 & 0.04 & {$[0.031 ; 0.202]$} \\
& Ketosis & 0.04 & 0.01 & {$[0.017 ; 0.067]$} \\
& Metritis & 0.02 & 0.01 & {$[0.011 ; 0.036]$} \\
& Retained placenta & 0.05 & 0.01 & {$[0.029 ; 0.081]$} \\
& Metabolic & 0.05 & 0.01 & {$[0.022 ; 0.076]$} \\
& Reproductive & 0.03 & 0.01 & {$[0.014 ; 0.040]$} \\
& Milk yield 1 & 0.13 & 0.01 & {$[0.112 ; 0.152]$} \\
& Milk yield 2 & 0.13 & 0.01 & {$[0.106 ; 0.147]$} \\
& Displaced abomasum & 0.10 & 0.03 & {$[0.039 ; 0.190]$} \\
Health-Lactation & Ketosis & 0.05 & 0.02 & {$[0.020 ; 0.090]$} \\
& Metritis & 0.02 & 0.01 & {$[0.012 ; 0.038]$} \\
& Retained placenta & 0.05 & 0.02 & {$[0.024 ; 0.080]$} \\
& Day in milk of peak milk yield ${ }^{4}$ & 0.02 & 0.01 & {$[0.011 ; 0.052]$} \\
& Peak milk yield ${ }^{4}$ & 0.19 & 0.06 & {$[0.161 ; 0.208]$} \\
& Lactation persistency ${ }^{4}$ & 0.34 & 0.01 & {$[0.310 ; 0.380]$} \\
\hline
\end{tabular}

${ }^{1}$ Heritability computed as $h^{2}=\frac{4 \sigma_{s}^{2}}{\sigma_{s}^{2}+\sigma_{h}^{2}+\sigma_{e}^{2}}$, where $\sigma_{s}^{2}$ is the sire additive genetic variance, $\sigma_{h}^{2}$ is the herd environmental variance, and $\sigma_{e}^{2}$ is residual variance.

${ }^{2}$ Results from the 4 analyses of Health-Culling analyses were very similar and only results from the analysis with displaced abomasum are given.

${ }^{3}$ Results from the 3 analyses of Health-MY analyses were very similar and only results from the analysis with displaced abomasum are given.

${ }^{4}$ Results from the 4 analyses of Health-Lactation analyses were very similar and only results from the analysis with displaced abomasum are given. 
Table 7. Posterior mean, standard deviation, and 95\% highest posterior density interval (95\% HPD) of genetic correlations of health disorders and production traits from Health-Culling, Health-Milk Yield (MY), and Health-Lactation analyses

\begin{tabular}{|c|c|c|c|c|}
\hline \multirow[b]{2}{*}{ Analysis } & \multirow[b]{2}{*}{ Traits $^{1}$} & \multicolumn{3}{|c|}{ Genetic correlations } \\
\hline & & Mean & $\mathrm{SD}$ & $95 \% \mathrm{HPD}$ \\
\hline \multirow[t]{4}{*}{ Health-Culling } & DA and culling & 0.80 & 0.20 & {$[0.431 ; 0.993]$} \\
\hline & KETO and culling & 0.76 & 0.17 & {$[0.415 ; 0.974]$} \\
\hline & METR and culling & 0.65 & 0.17 & {$[0.317 ; 0.927]$} \\
\hline & $\mathrm{RP}$ and culling & 0.69 & 0.19 & {$[0.284 ; 0.955]$} \\
\hline \multirow[t]{16}{*}{ Health-MY } & DA and KETO & 0.57 & 0.20 & $0.196 ; 0.901]$ \\
\hline & METR and RP & 0.49 & 0.16 & {$[0.185 ; 0.774]$} \\
\hline & META and REPRO & 0.26 & 0.18 & {$[-0.089 ; 0.596]$} \\
\hline & DA and MY1 & -0.28 & 0.26 & {$[-0.735 ; 0.252]$} \\
\hline & KETO and MY1 & 0.12 & 0.17 & {$[-0.209 ; 0.463]$} \\
\hline & METR and MY1 & -0.02 & 0.18 & {$[-0.365 ; 0.363]$} \\
\hline & RP and MY1 & -0.14 & 0.16 & {$[-0.440 ; 0.160]$} \\
\hline & META and MY1 & 0.01 & 0.02 & {$[-0.311 ; 0.345]$} \\
\hline & REPRO and MY1 & -0.06 & 0.16 & {$[-0.356 ; 0.244]$} \\
\hline & $\mathrm{DA}$ and MY2 & -0.28 & 0.26 & {$[-0.781 ; 0.219]$} \\
\hline & KETO and MY2 & 0.11 & 0.18 & {$[-0.231 ; 0.450]$} \\
\hline & METR and MY2 & -0.03 & 0.19 & {$[-0.396 ; 0.340]$} \\
\hline & $\mathrm{RP}$ and MY2 & -0.16 & 0.15 & {$[-0.471 ; 0.134]$} \\
\hline & META and MY2 & -0.01 & 0.17 & {$[-0.338 ; 0.339]$} \\
\hline & REPRO and MY2 & -0.07 & 0.16 & {$[-0.390 ; 0.222]$} \\
\hline & MY1 and MY2 ${ }^{2}$ & 0.99 & 0.01 & {$[0.980 ; 0.999]$} \\
\hline \multirow[t]{15}{*}{ Health-Lactation } & DA and PeakD & 0.18 & 0.42 & {$[-0.564 ; 0.870]$} \\
\hline & KETO and PeakD & -0.51 & 0.26 & {$[-0.934 ;-0.013]$} \\
\hline & METR and PeakD & 0.02 & 0.02 & {$[-0.013 ; 0.054]$} \\
\hline & RP and PeakD & 0.02 & 0.02 & {$[-0.023 ; 0.059]$} \\
\hline & DA and PMY & 0.12 & 0.33 & {$[-0.475 ; 0.748]$} \\
\hline & KETO and PMY & -0.20 & 0.19 & {$[-0.592 ; 0.206]$} \\
\hline & METR and PMY & 0.02 & 0.01 & {$[-0.001 ; 0.032]$} \\
\hline & $\mathrm{RP}$ and PMY & 0.02 & 0.01 & {$[-0.008 ; 0.033]$} \\
\hline & DA and LP & 0.12 & 0.29 & {$[-0.413 ; 0.683]$} \\
\hline & KETO and LP & -0.19 & 0.18 & {$[-0.585 ; 0.186]$} \\
\hline & METR and LP & 0.01 & 0.01 & {$[-0.004 ; 0.02]$} \\
\hline & RP and LP & 0.01 & 0.01 & {$[-0.003 ; 0.02]$} \\
\hline & PeakD and $\mathrm{PMY}^{3}$ & 0.72 & 0.34 & {$[-0.111 ; 0.983]$} \\
\hline & PeakD and $\mathrm{LP}^{3}$ & 0.61 & 0.29 & {$[-0.049 ; 0.908]$} \\
\hline & $\mathrm{PMY}$ and $\mathrm{LP}^{3}$ & 0.84 & 0.04 & {$[0.741 ; 0.906]$} \\
\hline
\end{tabular}

${ }^{1}$ Health disorders included were retained placenta (RP), metritis (METR), ketosis (KETO), displaced abomasum (DA), metabolic diseases (META), and reproductive disease (REPRO) and production traits included were milk yield 1 (MY1), milk yield 2 (MY2), day in milk of peak milk yield (PeakD), peak milk yield (PMY), and lactation persistency (LP).

${ }^{2}$ Results from the 3 analyses of Health-MY analyses were very similar and only results from the analysis with displaced abomasum are given.

${ }^{3}$ Results from the 4 analyses of Health-Lactation analyses were very similar and only results from the analysis with displaced abomasum are given.

of producer-recorded data, which may not reflect the "true" incidences of health disorders, which will somewhat underestimate the effect of subclinical cases. The posterior means of the structural coefficients show the small magnitude of recursive effects. Recursive effects from health disorders to LP were between -0.002 and 0.001 LP units. Similarly, recursive effects from health disorders to PeakD ranged from 0.018 to $0.095 \mathrm{~d}$. The recursive effects of health disorders on PMY were between -0.001 and $0.003 \mathrm{~kg}$. The recursive effects obtained in the above analysis were almost null. This suggests that cows affected by health disorders in early lactation could have recovered by the time production traits were recorded, whereas cows that did not recover may have been culled in early lactation.

\section{Heritabilities and Genetic Correlations}

Posterior means, SD, and 95\% HPD of heritabilities of liability of health disorders, culling, and production traits from all series of analyses are shown in Table 6. The heritabilities of liability to RP (0.054), METR (0.023), KETO (0.041), and DA (0.114) were within the range of previous threshold model estimates of heritability for these health disorders (Zwald et al., 2004a; Heringstad et al., 2005, 2009). Parker Gaddis et al. 
(2014) reported similar heritability estimates for health disorders using producer-recorded data. Heritability estimates of MY1 and MY2 were 0.132 and 0.127 , respectively. The heritability estimate obtained for PeakD was low (0.02). Muir et al. (2004) reported a larger estimated heritability of PeakD from first-lactation Canadian Holsteins (0.09). The heritability estimate of PMY was approximately 0.19 , which was lower than reported by Zwald et al. (2003; 0.27 to 0.37 ) or Rekaya et al. (2000; 0.26) and slightly higher than that of Ferris et al. $(1985 ; 0.16)$. The heritability estimate of LP was approximately 0.34 , which was higher than that obtained by Cole and VanRaden (2006), who estimated heritability of lactational persistency to be 0.10 .

The posterior mean of genetic correlations as well as 95\% HPD intervals of health disorder traits and production traits from all series of analyses are given in Table 7. The strongest genetic correlation was found for KETO with DA, with genetic correlations of approximately 0.57 . Similarly, a positive genetic correlation was found for RP with METR (0.49). Koeck et al. (2012) reported high genetic correlations between KETO and DA (0.64) and between RP and METR (0.61) in a study of Canadian Holsteins. Similarly, Heringstad (2010) reported a positive genetic correlation (0.64) between RP and METR. The 95\% HPD for genetic correlations of RP and METR with PeakD, PMY, and LP included zero in the credible interval. Negative genetic correlation estimates were found for KETO and PeakD (-0.51). The 95\% HPD for genetic correlations of KETO with PMY and LP, and DA with PeakD, PMY, and LP included zero in the credible interval. Genetic correlations between different fertility traits and LP were reported by Muir et al. (2004) and ranged from -0.09 to 0.23 . Jakobsen et al. (2003) found an unfavorable genetic correlation between health traits and LP.

The posterior mean of genetic correlation for production traits including MY1 and MY2 was positive and strong (0.99), as expected. Similarly, the estimate of genetic correlation between PMY and LP was positive and strong (0.84). The 95\% HPD for genetic correlation of PeakD with PMY and LP included zero in the credible interval. However, the mean of genetic correlation of PeakD with LP suggested a positive genetic correlation $>0.50$. Muir et al. (2004) reported a genetic correlation of PeakD with LP of approximately 0.54 for first-lactation Canadian Holstein cows. The genetic correlation results in our analysis indicate evidence of a genetic correlation between RP and METR and between KETO and DA, and most of the genetic correlations of health disorders with production traits included zero in 95\% HPD credible interval.

\section{CONCLUSIONS}

Inferring relationships between reproductive and metabolic health disorders could help us to identify development of the disease process. Consequences of diseases on culling and production traits were found to be important. The causal relationship between metabolic and reproductive health disorders and culling found in this study suggest that increases in the incidence of health disorders result in an increase in culling in early lactation. Similarly, the causal relationships among health disorders found in this study indicate that having one health disorder at an earlier time in a cow's productive life increases the risk of future health disorders. Recursive effects were not detected from reproductive and metabolic health disorders to production traits for cows who survived these health disorders.

\section{ACKNOWLEDGMENTS}

The authors thank Dairy Records Management Systems (Raleigh, NC) for providing the data, and XiaoLin Wu (Neogen/GeneSeek, Lincoln, NE) for providing software and assistance.

\section{REFERENCES}

Animal Improvement Programs Laboratory. 2006. Format 4: Lactation. Accessed Oct. 18, 2013. http://www.aipl.arsusda.gov/ CF-RCS/GetRCS.cfm?DocType $=$ formats\&DocName=fmt4.html.

Animal Improvement Programs Laboratory. 2010. Format 6: Health records. Accessed Oct. 18, 2013. http://www.aipl.arsusda.gov/ CF-RCS/GetRCS.cfm?DocType $=$ formats\&DocName=fmt6.html.

Animal Improvement Programs Laboratory. 2013. List of reference notes for format 4 as of: 2013-10-18. Accessed Oct. 18, 2013. http://aipl.arsusda.gov/CF-RCS/GetAllRef.cfm?docname=fmt4. html\&format $=$ fmt $4 \&$ title $=$ List of Reference Notes for Format 4\&NextChangeDate=2013-10-18.

Appuhamy, J. A. D. R. N., B. G. Cassell, and J. B. Cole. 2009. Phenotypic and genetic relationships of common health disorders with milk and fat yield persistencies from producer-recorded health data and test-day yields. J. Dairy Sci. 92:1785-1795.

Beaudeau, F., H. Seegers, V. Ducrocq, C. Fourichon, and N. Bareille. 2000. Effect of health disorders on culling in dairy cows: A review and a critical discussion. Ann. Zootech. 49:293-311.

Bigras-Poulin, M. 1985. Interrelationships among calving events, selected health problems, milk production, disposal and death in Ontario Holstein cows. PhD Thesis. University of Guelph, Guelph, ON, Canada.

Britt, J. H. 1985. Enhanced reproduction and its economic implications. J. Dairy Sci. 68:1585-1592.

Cobo-Abreu, R., S. Martin, R. Willoughby, and J. Stone. 1979. The association between disease, production and culling in a university dairy herd. Can. Vet. J. 20:191-195.

Cole, J. B., and P. VanRaden. 2006. Genetic evaluation and best prediction of lactation persistency. J. Dairy Sci. 89:2722-2728.

Cole, J., and P. VanRaden. 2007. A manual for use of BESTPRED: A program for estimation of lactation yield and persistency using best prediction. Animal Improvement Programs Laboratory, Agricultural Research Service, Beltsville, MD.

Congleton, W. Jr., and L. King. 1984. Profitability of dairy cow herd life. J. Dairy Sci. 67:661-674. 
Dechow, C. D., and R. Goodling. 2008. Mortality, culling by sixty days in milk, and production profiles in high- and low-survival Pennsylvania herds. J. Dairy Sci. 91:4630-4639.

Dhakal, K., C. Maltecca, J. P. Cassady, G. Baloche, C. M. Williams, and S. P. Washburn. 2013. Calf birth weight, gestation length, calving ease, and neonatal calf mortality in Holstein, Jersey, and crossbred cows in a pasture system. J. Dairy Sci. 96:690-698.

Drackley, J. 2006. Advances in transition cow biology: New frontiers in production diseases. Pages 24-34 in Production Disease in Farms Animals. Wageningen Academic Publishers, Wageningen, the Netherlands.

Duffield, T., and T. Herdt. 2000. Subclinical ketosis in lactating dairy cattle. Vet. Clin. North Am. Food Anim. Pract. 16:231-253.

Esposito, G., P. C. Irons, E. C. Webb, and A. Chapwanya. 2014. Interactions between negative energy balance, metabolic diseases, uterine health and immune response in transition dairy cows. Anim. Reprod. Sci. 144:60-71.

Ferris, T. A., I. Mao, and C. Anderson. 1985. Selecting for lactation curve and milk yield in dairy cattle. J. Dairy Sci. 68:1438-1448.

Geweke, J. 1992. Evaluating the accuracy of sampling-based approaches to the calculation of posterior moments. Pages 169-193 in Bayesian Statistics 4. J. M. Bernardo, J. Berger, A. P. Dawid, and A. F. M. Smith, ed. Oxford University Press, Oxford, UK.

Gianola, D., and D. Sorensen. 2004. Quantitative genetic models for describing simultaneous and recursive relationships between phenotypes. Genetics 167:1407-1424.

Gröhn, Y. T., S. Eicker, V. Ducrocq, and J. Hertl. 1998. Effect of diseases on the culling of Holstein dairy cows in New York State. J. Dairy Sci. 81:966-978.

Heringstad, B. 2010. Genetic analysis of fertility-related diseases and disorders in Norwegian Red cows. J. Dairy Sci. 93:2751-2756.

Heringstad, B., Y. Chang, D. Gianola, and G. Klemetsdal. 2005. Genetic analysis of clinical mastitis, milk fever, ketosis, and retained placenta in three lactations of Norwegian Red cows. J. Dairy Sci. 88:3273-3281.

Heringstad, B., X. L. Wu, and D. Gianola. 2009. Inferring relationships between health and fertility in Norwegian Red cows using recursive models. J. Dairy Sci. 92:1778-1784.

Jakobsen, J. H., R. Rekaya, J. Jensen, D. Sorensen, P. Madsen, D. Gianola, L. G. Christensen, and J. Pedersen. 2003. Bayesian estimates of covariance components between lactation curve parameters and disease liability in Danish Holstein cows. J. Dairy Sci 86:3000-3007.

Koeck, A., F. Miglior, J. Jamrozik, D. Kelton, and F. Schenkel. 2013a. Genetic associations of ketosis and displaced abomasum with milk production traits in early first lactation of Canadian Holsteins. J. Dairy Sci. 96:4688-4696.

Koeck, A., F. Miglior, D. F. Kelton, and F. S. Schenkel. 2012. Health recording in Canadian Holsteins: Data and genetic parameters. J. Dairy Sci. 95:4099-4108.

Koeck, A., F. Miglior, S. Loker, D. F. Kelton, and F. S. Schenkel. 2013b. Genetic relationships of mastitis, cystic ovaries and lameness with milk yield and somatic cell score in first lactation Canadian Holstein. Dairy Cattle Breeding and Genetics Committee Agenda. Accessed Jul. 12, 2014. http://cgil.uoguelph.ca/dcbgc/ Agenda1302/agenda1302.htm.

Korsgaard, I. R., M. S. Lund, D. Sorensen, D. Gianola, P. Madsen, and J. Jensen. 2003. Multivariate Bayesian analysis of Gaussian, right censored Gaussian, ordered catergorical and binary traits using Gibbs sampling. Genet. Sel. Evol. 35:159-183.

Lewis, G. S. 1997. Uterine health and disorders. J. Dairy Sci. 80:984994.

López de Maturana, E., X. L. Wu, D. Gianola, K. A. Weigel, and G. J. M. Rosa. 2009. Exploring biological relationships between calving traits in primiparous cattle with a Bayesian recursive model. Genetics 181:277-287.

Muir, B. L., J. Fatehi, and L. Schaeffer. 2004. Genetic relationships between persistency and reproductive performance in first-lactation Canadian Holsteins. J. Dairy Sci. 87:3029-3037.
Oltenacu, P. A., A. Frick, and B. Lindhé. 1990. Epidemiological study of several clinical diseases, reproductive performance and culling in primiparous Swedish cattle. Prev. Vet. Med. 9:59-74.

Parker Gaddis, K. L., J. Cole, J. Clay, and C. Maltecca. 2012. Incidence validation and relationship analysis of producer-recorded health event data from on-farm computer systems in the United States. J. Dairy Sci. 95:5422-5435.

Parker Gaddis, K. L., J. Cole, J. Clay, and C. Maltecca. 2014. Genomic selection for producer-recorded health event data in US dairy cattle. J. Dairy Sci. 97:3190-3199.

Pearl, J. 2000. Causality: Models, reasoning and inference. Vol. 29. MIT Press, Cambridge, MA.

Plummer, M., N. Best, K. Cowles, K. Vines, D. Sarkar, and R. Almond. 2013. Package 'coda'. Accessed Jan. 12, 2014. http://cran.rproject.org/web/packages/coda/coda.pdf.

Raizman, E. A.. J. E. Santos, and M. C. Thurmond. 2002. The effect of left displacement of abomasum corrected by toggle-pin suture on lactation, reproduction, and health of Holstein dairy cows. J. Dairy Sci. 85:1157-1164.

Rajala, P. J., and Y. Gröhn. 1998. Effects of dystocia, retained placenta, and metritis on milk yield in dairy cows. J. Dairy Sci. 81:3172-3181

Rauw, W., E. Kanis, E. Noordhuizen-Stassen, and F. Grommers. 1998 Undesirable side effects of selection for high production efficiency in farm animals: A review. Livest. Prod. Sci. 56:15-33.

Rehbein, P., K. Brügemann, T. Yin, X. Wu, and S. König. 2013. Inferring relationships between clinical mastitis, productivity and fertility: A recursive model application including genetics, farm associated herd management, and cow-specific antibiotic treatments. Prev. Vet. Med. 112:58-67.

Rekaya, R., M. Carabaño, and M. Toro. 2000. Bayesian analysis of lactation curves of Holstein-Friesian cattle using a nonlinear model. J. Dairy Sci. 83:2691-2701.

Rosa, G. J. M., B. D. Valente, G. de los Campos, X. L. Wu, D. Gianola, and M. A. Silva. 2011. Inferring causal phenotype networks using structural equation models. Genet. Sel. Evol. 43:6.

Shipley, B. 2002. Cause and Correlation in Biology. Cambridge University Press, Cambridge, UK.

Simianer, H., H. Solbu, and L. Schaeffer. 1991. Estimated genetic correlations between disease and yield traits in dairy cattle. J. Dairy Sci. 74:4358-4365.

Spirtes, P., C. Glymour, and R. Scheines. 2000. Causation, Prediction and Search. MIT Press, Cambridge, MA.

Valente, B. D., G. J. M. Rosa, G. de Los Campos, D. Gianola, and M. A. Silva. 2010. Searching for recursive causal structures in multivariate quantitative genetics mixed models. Genetics 185:633644.

Wu, X. L., B. Heringstad, Y. M. Chang, G. De los Campos, and D. Gianola. 2007. Inferring relationships between somatic cell score and milk yield using simultaneous and recursive models. J. Dairy Sci. 90:3508-3521.

Wu, X. L., B. Heringstad, and D. Gianola. 2008. Exploration of lagged relationships between mastitis and milk yield in dairy cows using a Bayesian structural equation Gaussian-threshold model. Genet. Sel. Evol. 40:333-357.

Zwald, N. R., K. Weigel, Y. Chang, R. Welper, and J. Clay. 2004a Genetic selection for health traits using producer-recorded data. I. Incidence rates, heritability estimates, and sire breeding values. J. Dairy Sci. 87:4287-4294.

Zwald, N. R., K. Weigel, Y. Chang, R. Welper, and J. Clay. 2004b. Genetic selection for health traits using producer-recorded data. II. Genetic correlations, disease probabilities, and relationships with existing traits. J. Dairy Sci. 87:4295-4302.

Zwald, N. R., K. Weigel, W. Fikse, and R. Rekaya. 2003. Identification of factors that cause genotype by environment interaction between herds of Holstein cattle in seventeen countries. J. Dairy Sci. 86:1009-1018. 